\title{
Noise-level Characterization of Portable Electric-power Generators in North-Central Nigeria: A Brand-by-Brand Comparative-study
}

\author{
Osagie Ibhadode $^{1}$ A. A. Adekunle ${ }^{1}$ Y. K. Abimiku' ${ }^{2}$ \& N. M. Umeobika ${ }^{2}$ \\ ${ }^{1}$ Research Engineer, Building Research Department, Nigerian Building and Road Research Institute
} (NBRRI), Nigeria

${ }^{2}$ Research Officer, Science Laboratory Technology Research Department, Nigerian Building and Road Research Institute (NBRRI), Nigeria

\begin{abstract}
This two-year study presents the average experimental results/data obtained from twelve (12) scientific investigations sequentially conducted on the noise-levels of electric-power generators used in seven (7) major cities-[Abuja, Makurdi, Lokoja, Ilorin, Lafia, Minna and Jos] of North-Central Nigeria. Fifty (50) popular models of electric-power generators produced by ten (10) leading generator-brands which were imported to, and used within the study-area were first identified. Then, using the CR811C Noise meter, the Perceived Noise Level $\left(L_{p n}\right)$, Sound Pressure Level $\left(L_{p}\right)$ and Sound Power Level ( SWL) of each of the fifty electricpower generator-models were obtained twelve times through field measurements and computation; in addition to recording the 'Usage time-periods' and 'Rated electric-powers' during each investigation. After which, a collation and graphical illustration of the respective average values obtained, showed that: majority (80\%), two-thirds (66\%) and below half (42\%) of the total number of tested electric-power generator-models used (operated) in the study area did not conform to three (3) international noise emission requirements [i.e. ' $L_{P}>85 \mathrm{~dB}$ ' , ' $L_{P}>87 \mathrm{~dB}$ ' and ' $L_{P}>90 \mathrm{~dB}$ '], since most of the generators exceeded the standard 8-hour Recommended Noise Level ( RNL) specified by 'NIOSH', 'IOSH' and 'OSHA' for human safety respectively. Without doubts, this poses a serious health risk to the millions of people presently living in these North-Central Nigerian cities.
\end{abstract}

Key Words: Perceived Noise Level, Electric-power generator, Sound Pressure Level, Recommended Noise Level, Sound Power Level

\section{INTRODUCTION}

Presently, in many developing African countries including Nigeria, where adequate electricity supply tends to evade the populace and sadly remains an ambitious national dream, the citizenry has continued to explore all possible options/opportunities available to them, to independently provide electricity to meet their fast-growing energy needs. Thus, the consistent systemic failure on the part of the governments and civil authorities to effectively rise up to the challenge of providing adequate electric power supply, in these corruption-laden and technologically handicapped nations, have consequently forced their citizens to resort to the daily/hourly use (operation) of electricity generators as the main source of electric power supply to their offices/homes/buildings/apartments/business premises.

However, this over-dependence on electricity generators for domestic and industrial electric power generation on the part of the citizens of these African nations - particularly Nigeria, has its own inherent demerits which include: Noise pollution, Atmospheric pollution, serious financial implications (expenditures), ill-health and Climate change etc. Now, of critical importance to us in this research paper, are the Noise pollution/emission levels associated with the use/operation of Electricity-generators.

A three-year study conducted by Reference [1] on the Hazards Assessment Analyses of Fossil-fuel Electricity-generators used (operated) in three (3) south-southern Nigerian cities of Port Harcourt, Uyo and Calabar; amongst other things, showed that: Majority [i.e. 80.1\%] of all 68,400 households/buildings/premises/apartments that were surveyed (investigated) were 'Active Users of electricity-generators' and almost all [i.e. 94.8\%] were 'Potential Users of electricity-generators'. This study further 
revealed that: The mean (average) noise emission level [i.e. acoustic rating] of all 34,200 tested (studied) generators stood at $93 d B$.

Obviously, Electric-power generators are major sources of environmental pollution, since apart from the resulting unwanted vibrations, they are also common sources of both noxious gaseous pollutants and localized/community noise pollution. Actually, the overall noise emission of an electricity-generator is a function of the discrete contributory noise levels emitted from several of its sources (parts/components) including the engine, engine exhaust, cooling fan and alternator etc. These statements are clearly corroborated by the research findings of Reference [2], in which it was experimentally proven that, as much as $78 \%, 98 \%$ and $100 \%$ of electric-power generators commonly-used (operated) in the seven(7) south-southern Nigerian metropolitan cities [of Port-Harcourt, Uyo, Calabar, Benin-City, Asaba, Warri and Yenagoa] exhibited noise-emission levels that were larger (greater) than the Permissible Noise Emission Levels ( PNELs ) stipulated by the World Health Organization (WHO), United States Environmental Protection Agency ( USEPA) and European Norm ( EN ) respectively.

The use of electric-power generators for electricity by most Nigerian citizens has become a norm, thus the accompanying issues of possible electrocution and the occurrence of other electrical hazards like 'Electric-fire outbreak' during the installation of electric-power generators must never be overlooked, particularly in a country like Nigeria, where there is still a relatively high patronage of quack technicians/technologists/engineers. Sadly enough, in several observed cases of electrocution, harmful quantities (amounts) of electricity actually flowed through the victims' skins (bodies) which could be attributed to wet conditions and/or perspiration, in which case, it is important to note that, the human-body resistance is inversely proportional to the quantity (amount) of current that flows through the human body. [3]

Electric-power generators could explicitly be defined as all such devices/machines which are capable of converting mechanical energy to electrical energy, which will then be used to do useful work such as overcoming the electrical load of an external circuit. Typically, the source of the mechanical energy could actually differ from being a simple hand crank system to an outright Internal Combustion Engine. More often than not, the fuel that is used to drive an Internal Combustion Engine is a hydrocarbon-based fuel, which includes 'Automobile Gas oil' also called 'Diesel' and 'Premium Motor Spirit' also called 'Gasoline' etc., must first be combusted within the combustion chamber of the Internal Combustion Engine, to release the chemical energy of the hydrocarbon molecules, which is then converted to mechanical energy by doing the mechanical work of pushing the piston. Finally, this mechanical energy is then converted to electrical energy, using an alternating current (ac) dynamo.

Several researchers around the world have proven that there are serious negative health implications of noise pollution. According to [4] and [5]; prolonged exposure to environmental noise pollution amongst other things results in noise-induced hearing-loss ( NIHL), sleep disturbance increased incidence of diabetes, cardiovascular disease, Noise annoyance and endocrine effects [6]. Reference [7] showed that Noise brings about hearing loss \& damage; affects (interferes with) speech, mental concentration, work \& sleep; and results in stress, fatigue, irritation \& annoyance [8]. The Wikipedia Encyclopaedia in its 2016 publication on the Health Hazards of Noise Pollution, stated that: hearing loss, hearing impairment, hypertension, ischemic heart diseases, noise annoyance, sleep disturbance, changes in the human immune system, birth defects, Presbycusis [at old age], tinnitus, hypertension, vasoconstriction and other cardiovascular adverse effects etc., are all consequences of chronic exposure to noise [and especially at elevated sound levels] [2]. Furthermore, repetitive prolonged exposure to 'Unsafe noise' i.e. noise emissions [from machineries such aircrafts and electric-power generators or from other sources,] which exceed the global standards' recommended noise levels (such as the aforementioned 'PNELs') for human safety], would most likely result in one or more of speech-unintelligibility, sleep-disturbance, headache and noise-annoyance etc.[9]

Noise is said to be an undesired sound which is disharmonious and unpleasant or which distorts the hearing of undesirable sound [10],[11]. Noise could actually be defined as an unrequired sound and a form of energy, emitted by a source (vibrating body) which on reaching the human ear, results in a physical feeling (mental impression) of hearing via the ear, which is connected to the human nervous system [12]. Scientifically, Sound is the resulting consequence of changes in pressure travelling through a medium [particularly air], which is brought about by turbulence or vibration [13]. Very importantly, it should be noted that Reference [8] suggested that, Noise could be produced by forces or aerodynamic effects, which are consequences of a combustion process or rotating engine parts/components undergoing mechanical excitation. More specifically, environmental noise was defined by the World Health Organisation (WHO) as Sound emitted from all sources [including machines like Electricitygenerators], with exception to the industrial workplace [14]. 
These and a number of other uncited, but publicly available publications [revealing the risks of noise pollution and proving that Electricity-generators are major contributors to environmental noise pollution] coupled with the growing awareness of the advantages of a quiet environment; have only recently made it necessary for the users/consumers of manufactured products and the society in general, to clamour for quiet residential/work environments and quiet finished products [including electricitygenerators] [15].

Apart from ventilation whose vital contributory role of ensuring that the occupants of a building enjoy (have) an ideal 'Indoor Environmental Quality (IEQ)' [16], three other factors which also play a major role in ensuring that an ideal IEQ is achieved/attained are the building's indoor thermal comfort index, illumination (lighting) levels, and acoustic performancewhich itself could be significantly affected by the presence of localized environmental noise-emitters such as electric-power generators - hence, the need for this study.

Furthermore, the unavailability/scarcity of scientific research data on the major noise parameters of electric-power generators in Nigeria; have made it difficult for the average Nigerian to make the right choice with respect to acquiring and operating an electric-power generator, which is acoustically safe. Therefore, the aim of this research work, is to carry out a scientific study on three major noise parameters i.e. Sound Pressure Level $\left[L_{p}\right](d B)$, Perceived Noise Level $\left[L_{p n}\right](P N d B)$ and Sound Power Level [ $S W L]\left(W^{-2}\right)$ of fifty (50) different models/manufactured versions of ten (10) competing electricity-generator brands, used (operated) in seven (7) North-Central Nigerian cities [of Abuja, Makurdi, Lokoja, Ilorin, Lafia, Minna and Jos]; with a view to determining whether or not, they are within the Recommended Noise Levels ( RNLs ) by the NIOSH, IOSH and OSHA for eight (8) hour safe daily exposure.

\section{MATERIALS AND METHOD}

Using the integrated $C R 811 C$ Noise meters, the Sound Pressure Levels [ $\left.L_{p}\right]$ of all fifty (50) popular models of Electric-power generators produced by ten (10) different generator-brands imported to North-central Nigeria. The integrated $C R 811 C$ Noise meter is a type 1 integrated sound level meter which is specially designed and equipped with the capacity to obtain and record precise field measurements of time-integrated sound level values. Having a measurement accuracy of $\pm 1 d B$, it measures sound levels from a minimum of $21 \mathrm{~dB}$ to a maximum of $140 \mathrm{~dB}$, with a sound measurement frequency which ranges from $25 \mathrm{~Hz}$, to $16 \mathrm{~Hz}$. Furthermore, this precision sound level meter measures sound levels using the ' $A$ ' weighted scale of sound frequency, which is more often used than sound frequency weighting scales ' $B$ ' ' $C$ ' and, since it is most suitably similar to the usual behavioural-response (normal reaction) of the human ear to most sound frequencies.

Twelve (12) successive on-the-spot assessments of the noise emission levels of fifty (50) running (active) electric-power generator models were periodically carried-out within a study-duration (period) of two (2) years from $1^{\text {st }}$ June 2015 to $31^{\text {st }}$ May 2017 . These noise-levels assessments of the generator models were carried out between the hours of 8 am (0800 hours) and 6 pm (1800 hours) on each day, at fifty (50) carefully chosen generator-user location 'randomly spread across the study-area-the seven (7) major cities [i.e. 'Abuja' (in the Federal Capital Territory), 'Makurdi' (capital city of Benue state), 'Lokoja' (capital city of Kogi state), 'Ilorin' (capital city of Kwara state),' Lafia' (capital city of Nasarawa state), 'Minna' (capital city of Niger state) and 'Jos' (capital city of Plateau state)] all located in the North-central geo-political zone [sometimes called the 'Middle-belt region'] of Nigeria.

The choice of each generator-user location as being suitable for this study was hinged on the facts that: (1.) The generator was regularly in use (operation), (2.) The particular generator model was observed to be commonly acquired and used (operated) in the aforementioned seven major cities, and (3.) There was unrestricted (ease of) access to the operated (running) generator, by the research investigators. All measurements of generator noise emission levels were carried out: (1.) When there was no rain and/or wind, (2.) Far from reflective and/or hard surfaces, (3.) Under experimental conditions that eliminated sound wave interference(s) - be it constructive or destructive, and (4.) After calibrating the $C R 811 C$ Noise meter prior to the commencement of measurements.

For each of the fifty (50) investigated models of electric-power generators produced by ten (10) popularly imported generatorbrands to North-central Nigeria, 'Rated electric power' in ' $K W^{\prime}$, and 'Usage time-period' in 'Months' were initially noted and recorded during the first on-the-spot assessment of the generators. Both parameters were accordingly noted and recorded during 
the subsequent on-the-spot assessment of the generators, after which, the average values of both parameters were then calculated and used for this study.

Also, the automatic mode configuration of the $C R 811 C$ Noise level meter was first activated, so as to take measurements for sixty (60) minutes continuously. Then, with the antenna of the noise level meter pointing in the direction of the of the running (operational) electric-power generator, five (5) consecutive measurements of 'Sound Pressure Level [ $L_{p}$ ]' in ' $d B$ ' were taken at a fixed distance of one meter $(1 \mathrm{~m})$ from each generator, on each of its four (4) sides. In addition, after obtaining the 'Noisiness' of each electric-power generator as a conversion of the Sound Pressure Level $\left[L_{p}\right]$ with the aid of the 'Kryter Scale (1959)' in accordance with 'ISO-R507 (1966)'; each generator's 'Perceived Noise Level [ $\left.L_{p n}\right]$ ' expressed in 'PNdB' was obtained from the Sound Pressure Level and Noisiness at $1000 \mathrm{~Hz}$ corresponding to the 'Noy scale'.

Moreover, the Sound Power Level [ $S W L$ ] of each electric-power generator expressed in ' $W m^{-2}$ ' was calculated using 'equation

(1)' which shown below:

$$
S W L=S P L+10 \log _{10} 4 \pi r^{2}-\cdots-(1)[17]
$$

Where:

' $S W L$ ' is the unknown 'Sound Power Level' to be calculated in ' $W m^{-2}$ ',

'SPL' is the already known (measured) 'Sound Pressure Level' being expressed in ' $d B$ ', and

' $r$ ' is the distance in ' $m$ ' from the antenna of the Noise-level meter to the running (operational) generator, which was kept constant at $1 \mathrm{~m}$, during all measurements.

Furthermore, all the values so obtained were then recorded, collated and graphically illustrated. Thus, the various generator models produced by each of the ten (10) selected generator brands were lumped together and then, the measured and calculated values of ' $L_{p}$ ', ' $L_{p n}$ ' , 'SWL', 'Rated electric power' and 'Usage time-period' for the various generator models which they produce, were collectively inputted (used) to plot ten (10) illustrative charts showing the specific values/ranges of the abovementioned noise parameters, and how they differed from the 'Standard 8-hour Recommended daily Noise exposure Level/value ( $R N L$ )' specified by three (3) widely acclaimed and time-tested global standardization bodies/organizations - the US-based 'National Institute for Occupational Safety \& Health ( NIOSH )', the UK-based 'Institution of Occupational Safety \& Health ( $I O S H$ )' and the US-based 'Occupational Safety \& Health Administration (OSHA)'.

At this juncture, it might be pertinent to specifically state the maximum values of the 'Standard 8-hour Recommended daily Noise exposure Level/value ( $R N L)$ ' for the three (3) critical noise parameters [ $L_{p}{ }^{\prime},{ }^{\prime} L_{p n}$ ' and ' $S W L$ '], as specified by the abovementioned three standard regulatory bodies/organizations as follows:

i. $\quad$ Maximum Sound Pressure Level $\left[L_{p}\right]$ for 8-hour safe daily human exposure:

NIOSH specifies ' $85 \mathrm{~dB}$ ', IOSH specifies ' $87 \mathrm{~dB}$ ', while $O S H A$ specifies '90dB';

ii. $\quad$ Maximum Perceived Noise Level [ $L_{p n}$ ] for 8-hour safe daily human exposure:

NIOSH specifies '102.8PNdB', IOSH specifies '104.5dB', while $O S H A$ specifies '107.9dB'; and

iii. $\quad$ Maximum Sound Power Level [ $S W L$ ] at a 1m distance for 8-hour safe daily human exposure:

NIOSH specifies '96Wm $\mathrm{Wm}^{-2}$, IOSH specifies ' $98 \mathrm{Wm}^{-2}$ ', while $O S H A$ specifies '101dB'.

More so, the aforementioned charts which are displayed below, clearly show the variation patterns of the three (3) noise parameters, 'Rated electric power' and 'Usage time-period' of each generator brand with time. Finally, direct comparative analysis 
of the magnitudes of these three noise parameters [ $L_{p}{ }^{\prime},{ }^{\prime} L_{p n}{ }^{\prime}$, and ' $S W L$ '] for the various generator-models is reported on a brand-by-brand basis.

\section{RESULTS AND DISCUSSION}

Below are then (10) graphical charts labelled from 'Figures 1-10', each of which summarily illustrates the variations of Perceived Noise Level ( $L_{p n}$ ), Sound Pressure Level $\left(L_{p}\right)$ and Sound Power Level ( $S W L$ ) of the considered electric-power generator-models produced by each of the ten (10) leading electric-power generator-brands in North-Central Nigeria, with respect to the standard values specified by ' $N I O S H$ ', 'IOSH' and ' $O S H A$ '; in addition to 'Rated electric-power' and 'Usage time-period'.

\subsection{Generator-brands ' 1 ', '2' and '3':}

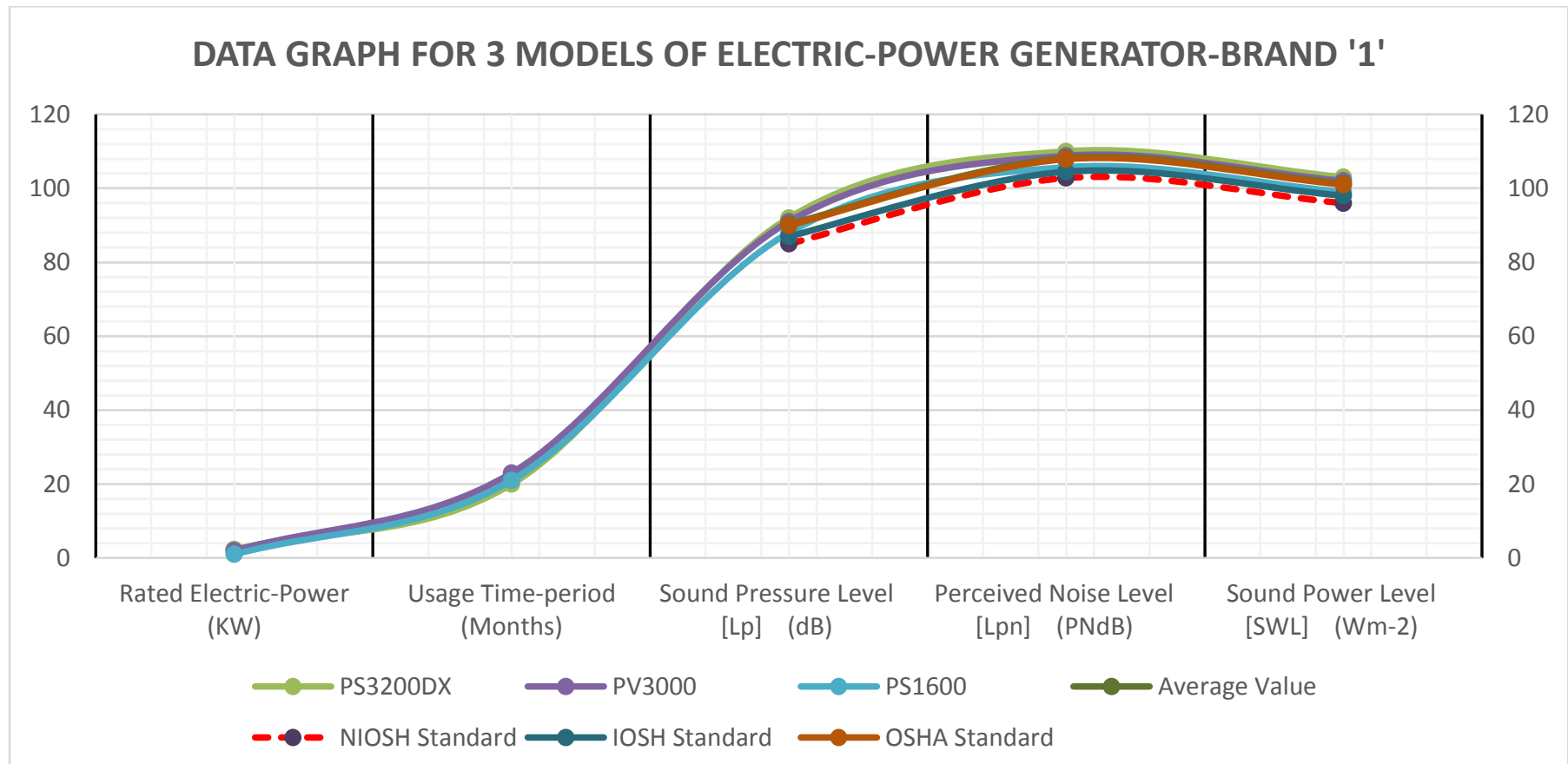

Figure1: Rated Electric-power, Usage Time-period \& Noise parameters of 3 Models manufactured by Generator-brand 1

Figures 1-3 summarily illustrate the selected noise parameters and usage information data of fifteen (15) Models of generators manufactured by three (3) Generator-brands i.e. three (3) models of Generator-brand '1' shown in figure 1, seven (7) models of Generator-brand '2' shown in figure 2, and five (5) Models of Generator-brand ' 3 ' shown in figure 3. For all three products/technologies, the Rated electric-power ranges were: $1.0 \mathrm{KW}-2.3 \mathrm{KW}, 0.5 \mathrm{KW}-5.0 \mathrm{KW}$ and $1.0 \mathrm{KW}-9.6 \mathrm{KW}$ respectively; and Usage time durations ranged between 20months-23months, 13months-24months, and 14months-21months respectively. 


\section{DATA GRAPH FOR 7 MODELS OF ELECTRIC-POWER GENERATOR-BRAND '2'}

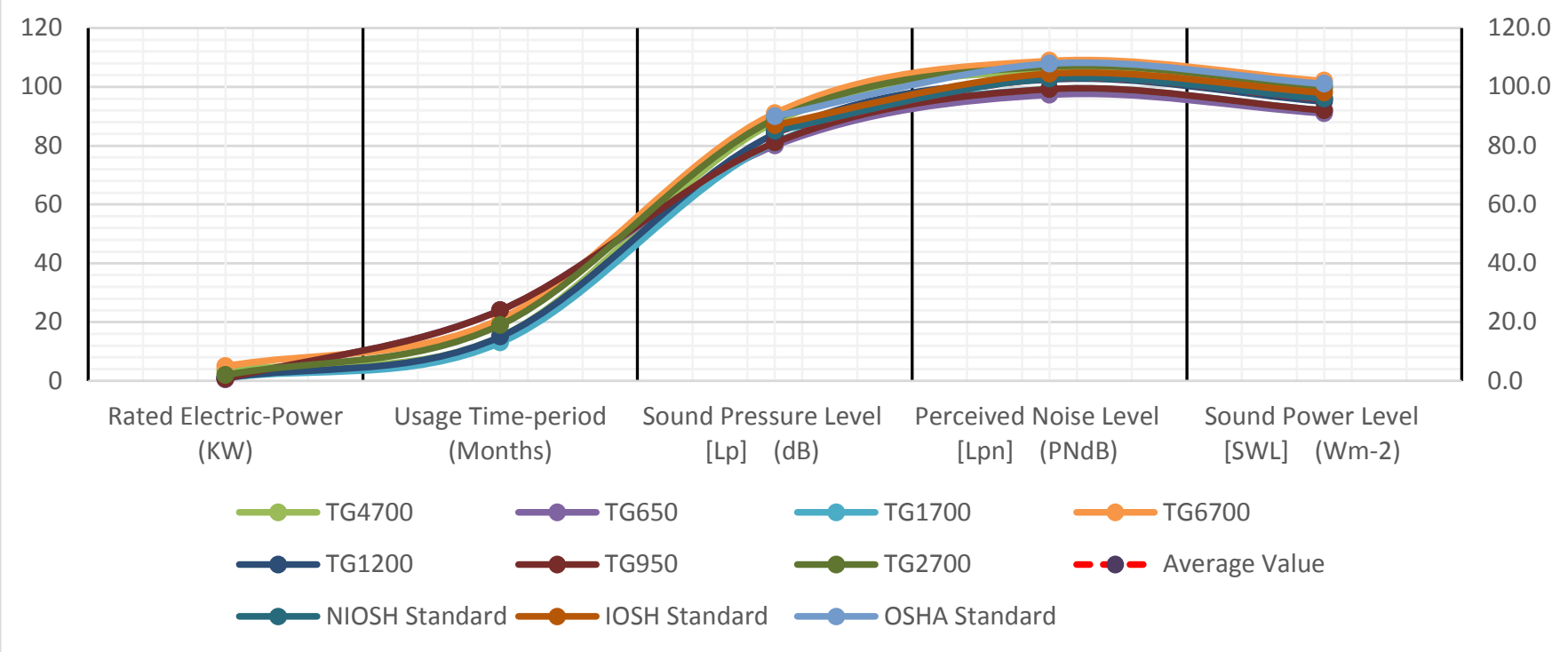

Figure2: Rated Electric-power, Usage Time-period \& Noise parameters of 7 Models manufactured by Generator-brand 2

Also, for all three Generator-brands, majority of the values of both Perceived Noise Level ( $\left.L_{P N}\right)$ and Sound Power Level ( $S W L$ ) which were respectively obtained as variables dependent on the Sound Pressure Level $\left(L_{P}\right)$, were noted to have significantly deviated from the values recommended by the standards i.e.' $N I O S H$ ', ' $I O S H$ ' and 'OSHA' as listed in the $8^{\text {th }}$ paragraph of 'Section 3', (i.e. 'Materials and Method') above. This was because the Perceived Noise Level ( $\left.L_{P N}\right)$ values of the fifteen (15)

Models produced by these three (3) Generator-brands/technologies were: 110.0PNdB (PS3200DX), 108.8PNdB (PV3000) \& 105.7PNdB ( PS1600) [for Generator-brand '1']; 105.7PNdB (TG4700), 97.3PNdB (TG650), 99.2PNdB ( TG1700), $108.8 P N d B$ (TG6700), 102.5PNdB (TG1200), 99.2PNdB ( TG950) \& 106.9PNdB (TG2700) [for Generator-brand ' 2 ']; and 91.0PNdB (VPG2400), 116.5PNdB (ECO10990ES), 111.0PNdB (EPG3910EX), 116.5PNdB (ECO8990ES) \& 91.0PNdB ( EPG2400) [for Generator-brand ' 3 ']. Thus, it was observed that, three (3) Models of each of these three (3) Generator-brands i.e. [ $P S 3200 D X$ (110.0PNdB ), PV3000 (108.8PNdB) and PS1600 (105.7PNdB) of Generator-brand '1']; $T G 4700$ (105.7PNdB), TG6700 (108.8PNdB) and TG2700 (106.9PNdB) of Generator-brand '2']; and [ ECO10990ES (116.5PNdB), EPG3910EX ( $111.0 P N d B$ ) and ECO8990ES (116.5PNdB) of Generator-brand '3'] had $L_{P N}$-values that clearly exceeded the corresponding $N I O S H$ and IOSH $L_{P N}$-values of $102.8 P N d B$ and 104.5PNdB respectively; while two (2) Models of Generator-brand '1' [ $P S 3200 D X(110.0 P N d B)$ and $P V 3000$ (108.8PNdB )], one (1) Model of Generator-brand '2' [TG6700 (108.8PNdB )], and three (3) Models of Generator-brand '3' [ ECO10990ES (116.5PNdB ), EPG3910EX (111.0PNdB) and ECO8990ES ( $116.5 P N d B$ )] had $L_{P N}$-values that exceeded the $O S H A L_{P N}$-value of $107.9 P N d B$. 


\section{DATA GRAPH FOR 5 MODELS OF ELECTRIC-POWER GENERATOR-BRAND '3'}

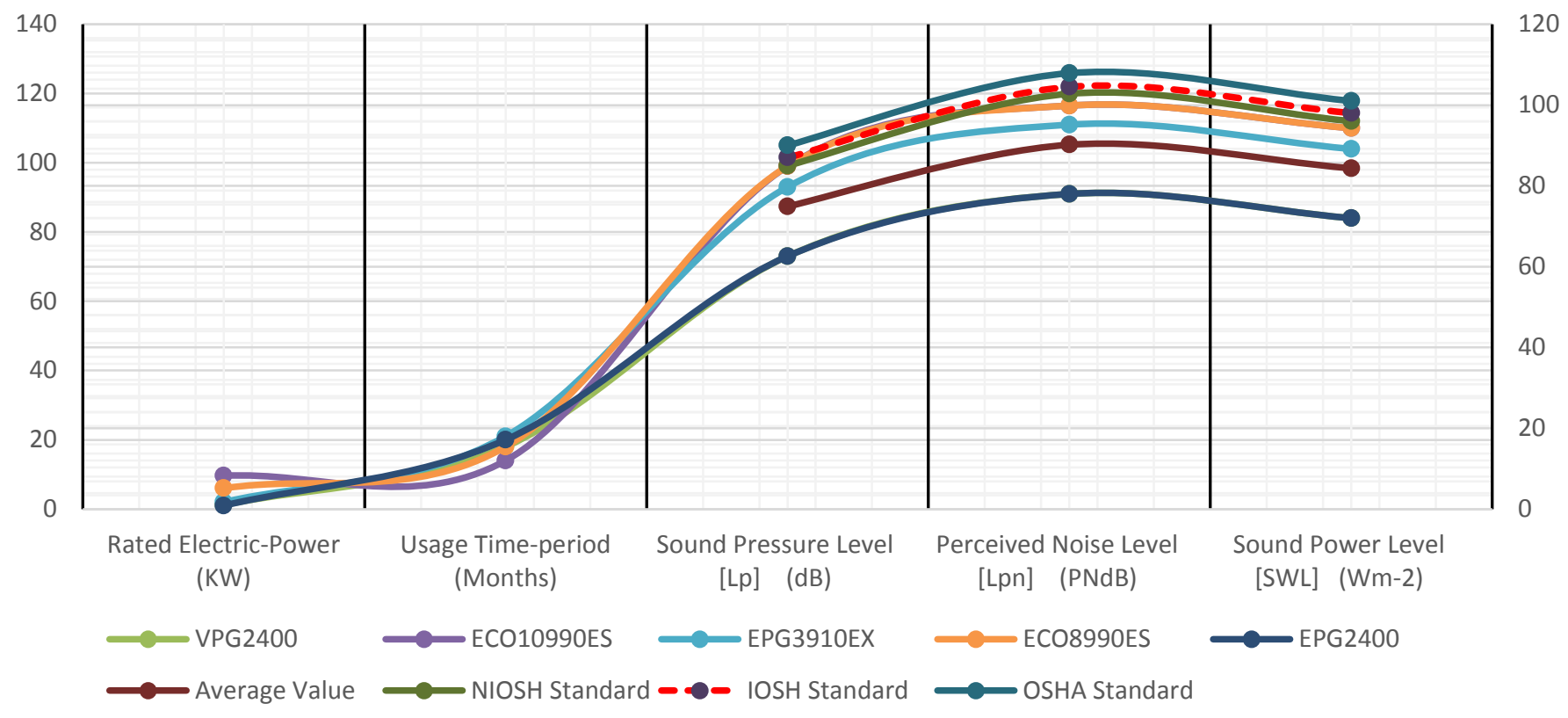

Figure3: Rated Electric-power, Usage Time-period \& Noise parameters of 5 Models manufactured by Generator-brand 3

Likewise, the Sound Power Levels ( SWL) for the three Generator-brands were calculated to be: $103 W m^{-2}$ (PS3200DX), $102 \mathrm{Wm}^{-2}$ ( PV3000) \& 99 $\mathrm{Wm}^{-2}$ ( PS1600) [for the three Models of Generator-brand '1']; 99 $\mathrm{Wm}^{-2}$ ( TG4700), 91Wm ${ }^{-2}$ ( TG650), 92 $\mathrm{Wm}^{-2}$ ( TG1700), 101Wm $\mathrm{Wm}^{-2}$ ( TG6700), 95Wm $\mathrm{Wm}^{-2}$ TG1200), 92 $\mathrm{Wm}^{-2}$ ( TG950), \& 100 $\mathrm{Wm}^{-2}$ (TG2700) [for the seven Models of Generator-brand '2']; and 84Wm ${ }^{-2}$ ( VPG2400), 110 $\mathrm{Wm}^{-2}$ ( ECO10990ES), 104Wm-2 ( EPG3910EX), $110 \mathrm{Wm}^{-2}$ (ECO8990ES), \& 84Wm${ }^{-2}$ ( EPG2400) [for the five Models of Generator-brand '3'], respectively. Majority of these values conformed to the three Standards since they were lower than/equal to the corresponding NIOSH, IOSH and OSHA Sound Power Levels of $96 \mathrm{Wm}^{-2}, 98 \mathrm{Wm}^{-2}$ and $101 \mathrm{Wm}^{-2}$ respectively.

However, for each of the three Generator-brands, it was observed that, three Models i.e. [PS3200DX ( $92 d B$ ), PV3000 (91dB), \& PS $1600(88 d B)$ of Generator-brand1]; [TG4700 ( $88 d B$ ), TG6700 (90dB) \& TG2700 (89dB) of Generator-brand 2], and [ECO10990ES (99dB), EPG3910EX (93dB ) \& ECO8990ES (99dB) of Generator-brand 3] emitted sounds with Sound Pressure Levels $\left(L_{P}\right)$ which were above the NIOSH Recommended Noise Levels ( $R N L$ ) of $85 \mathrm{~dB}$ and the IOSH Recommended Noise Levels ( $R N L)$ of $87 d B$ for 8hour daily exposure. While two Models of Generator-brand 1 [PS3200DX (92dB) \& PV3000 ( 91dB)], one Model of Generator-brand 2 [TG6700 (91dB)], and three Models of Generator-brand 3 [ECO10990ES (99dB), EPG3910EX (93dB) \& ECO8990ES ( $99 d B$ )], emitted sounds with $L_{P}$-values that exceeded the $O S H A$ recommended $L_{P}$-value of $90 \mathrm{~dB}$ for 8hour daily exposure. 


\subsection{Generator-brands ' 4 ', '5' and ' 6 ':}

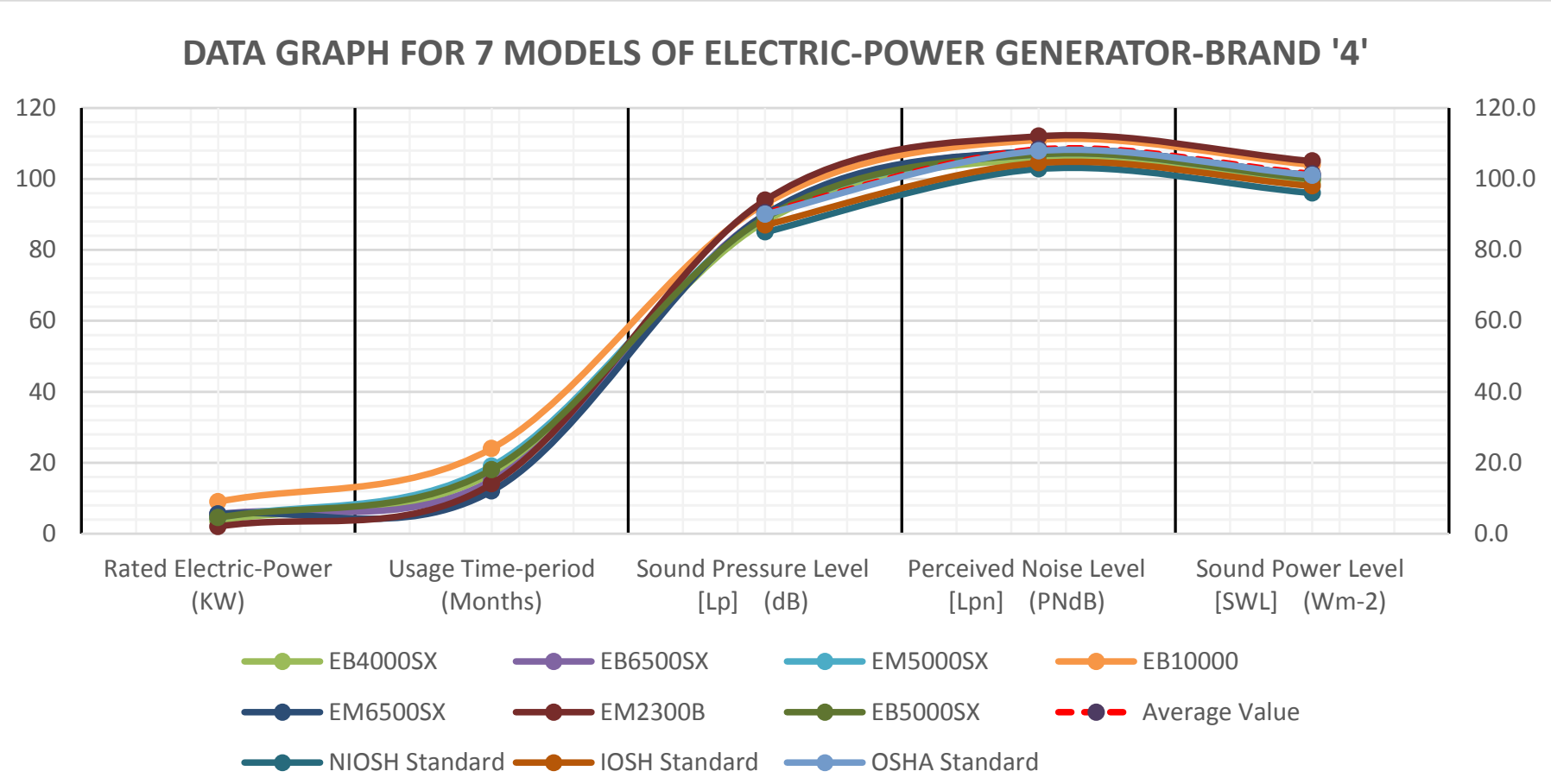

Figure4: Rated Electric-power, Usage Time-period \& Noise parameters of 7 Models manufactured by Generator-brand 4

A similar consideration of Figure 4, Figure 5 and Figure 6, consecutively, revealed the following facts. First and foremost, the seven Models manufactured by Generator-brand '4' had Rated electric -powers ranging from $2.0 \mathrm{KW}-9.0 \mathrm{KW}$, and were used for different time durations ranging between 12months-24months shown in figures 4 . On the other hand, the six Models of Generator-brand ' 5 ' had a Rated electric-power range of $3.3 \mathrm{KW}-6.8 \mathrm{KW}$, and were used for time durations ranging from 17months-24months as shown in figure 5. Also, for the five Models produced by Generator-brand ' 6 ', Rated electric-power range stood at $1.0 \mathrm{KW}-6.0 \mathrm{KW}$ while usage time duration range was 12 months -22 months as shown in figure 6 .

\section{DATA GRAPH FOR 6 MODELS OF ELECTRIC-POWER GENERATOR-BRAND \\ '5'}

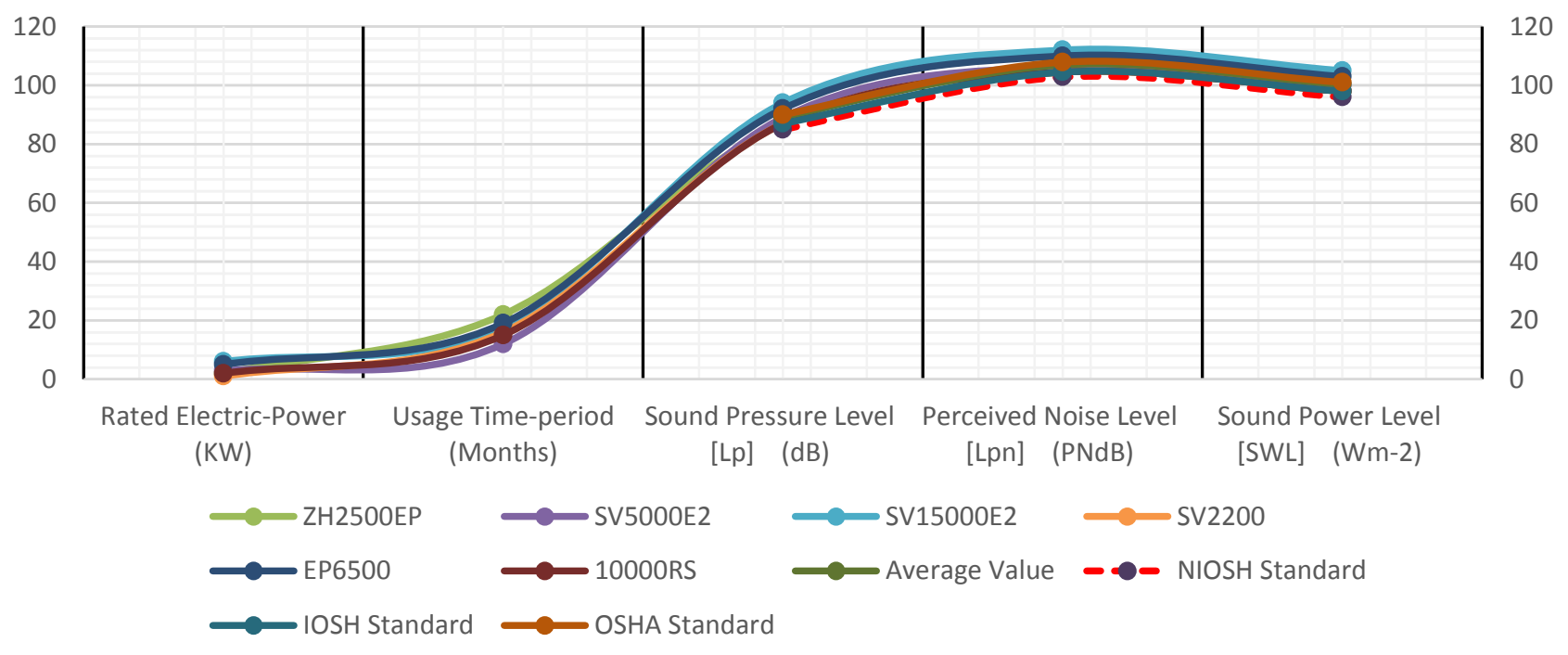

Figure5: Rated Electric-power, Usage Time-period \& Noise parameters of 6 Models manufactured by Generator-brand 5 
The Perceived Noise Levels $\left(L_{P N}\right)$ obtained for the various Models, produced by each of these three Generator-brands were: 105.7PNdB (EB4000SX), 107.9PNdB (EB6500SX), 106.9PNdB (EM5000SX), 111.0PNdB (EB10000), 107.9PNdB (EM6500SX), 112.0PNdB (EM2300B) \& 106.9PNdB (EB5000SX) [for Generator-brand '4']; 106.9PNdB (3800ES), 110.0PNdB ( 4400RS), 111.0PNdB ( 7500RS), 111.0PNdB (8100RS), 111.0PNdB (9200RS), \& 112.0PNdB (10000RS) [for Generator-brand '5']; and 104.5PNdB (ZH2500EP), 106.9PNdB (SV5000E2), 112.0PNdB (SV15000E2), 104.5PNdB (SV2200), 110.0PNdB (EP6500) \& 104.5PNdB (SV3800E2) [for Generator-brand '6']. The above values indicated that for both Generatorbrand ' 4 ' and Generator-brand '5', seven (7) Models exceeded the corresponding NIOSH $L_{P N}$-value of 102.8PNdB, and six (6) Models exceeded the corresponding IOSH $L_{P N}$-value of $104.5 P N d B$. Then, two Models of Generator-brand '4', and five Models of Generator-brand ' 5 ' exceeded the $O S H A L_{P N}$-value of 107.9PNdB. However, in the exclusive case of Generatorbrand ' 6 ', six, three and two Models gave $L_{P N}$-values which clearly exceeded the corresponding values of $102.8 P N d B$, 104.5PNdB and 107.9PNdB specified by the NIOSH, IOSH and OSHA respectively.

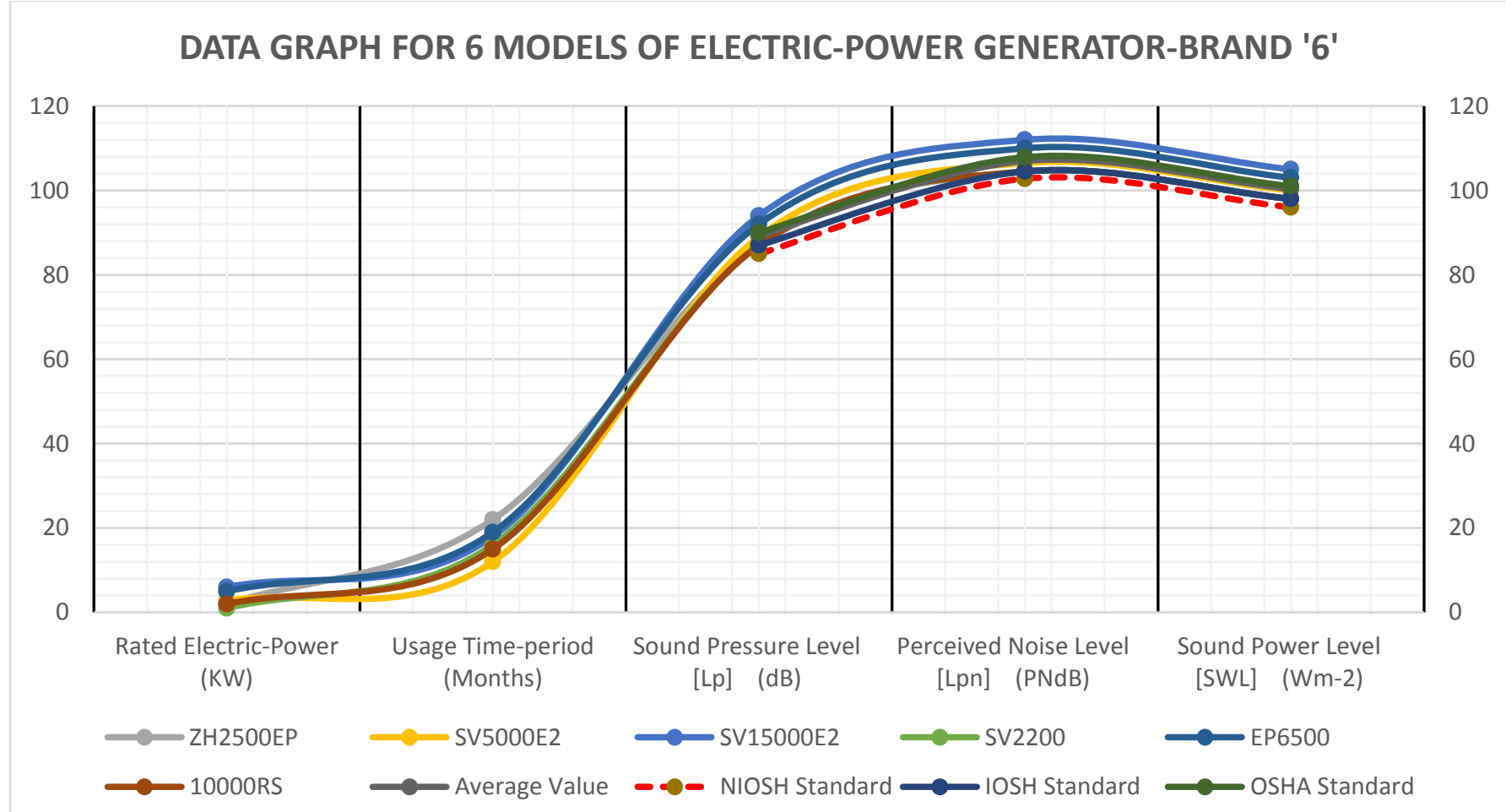

Figure6: Rated Electric-power, Usage Time-period \& Noise parameters of 6 Models manufactured by Generator-brand 6

Moreover, the above trend of an upward deviation of the majority of the Perceived Noise Level ( $\left.L_{P N}\right)$ values [of the electricity generators] from those values specified by the three standards, was similarly noticed with the Sound Power Levels ( SWL ). Now, the computed Sound Power Levels ( $S W L$ ) of the various models of electricity-generators manufactured by these three Generatorbrands were: $99 \mathrm{Wm}^{-2}$ (EB4000SX), 101Wm ${ }^{-2}$ (EB6500SX), 100 $\mathrm{Wm}^{-2}$ ( EM5000SX), 104Wm ${ }^{-2}$ (EB10000), 101Wm (EM6500SX), 105 $\mathrm{Wm}^{-2}$ (EM2300B), \& 100 $\mathrm{Wm}^{-2}$ ( EB5000SX) [for the seven Models of Generator-brand '4']; 100Wm ${ }^{-2}$ (3800ES), 103 $\mathrm{Wm}^{-2}$ (4400RS), 104Wm $\mathrm{Wm}^{-2}$ (7500RS), 104Wm $\mathrm{Wm}^{-2}$ (8100RS), 104Wm $\mathrm{Wm}^{-2}$ (9200RS), \& 105Wm $\mathrm{Wm}^{-2}(10000 \mathrm{RS})[\mathrm{for}$ the six Models of Generator-brand ' 5 ']; and $98 \mathrm{Wm}^{-2}$ (ZH2500EP), 100Wm ${ }^{-2}$ (SV5000E2), 105Wm ${ }^{-2}$ (SV15000E2), 98Wm ${ }^{-2}$ (SV2200), 103Wm $\mathrm{Wm}^{-2}$ (EP6500) \& 98Wm-2 (SV3800E2) [for the six Models of Generator-brand '6'], respectively. A comparison 
of the above-calculated values of generators' SWL indicated that: all seven (7) Models of Generator-brand '4' and all six (6) Models of Generator-brand '5' emitted sounds with SWL values that exceeded the corresponding NIOSH and OSHA standard SWL recommendations of $96 \mathrm{Wm}^{-2}$ and $98 \mathrm{Wm}^{-2}$ respectively. However, two Models of Generator-brand '4' and five Models of Generator-brand ' 5 ' had $S W L$ values which were larger than the $O S H A$ standard $S W L$ recommendation of $101 W m^{-2}$. In addition, an exclusive consideration of only the Generator-brand '6', showed that six, three and two Models gave $S W L$-values which were obviously larger than all three (3) recommended $S W L$ values of: $96 \mathrm{Wm}^{-2}$ [ $\mathrm{NIOSH}$ standard], 98Wm ${ }^{-2}$ [ IOSH standard] and $101 \mathrm{Wm}^{-2}$ [OSHA standard] respectively.

\subsection{Generator-brands '7', '8', '9' and '10':}

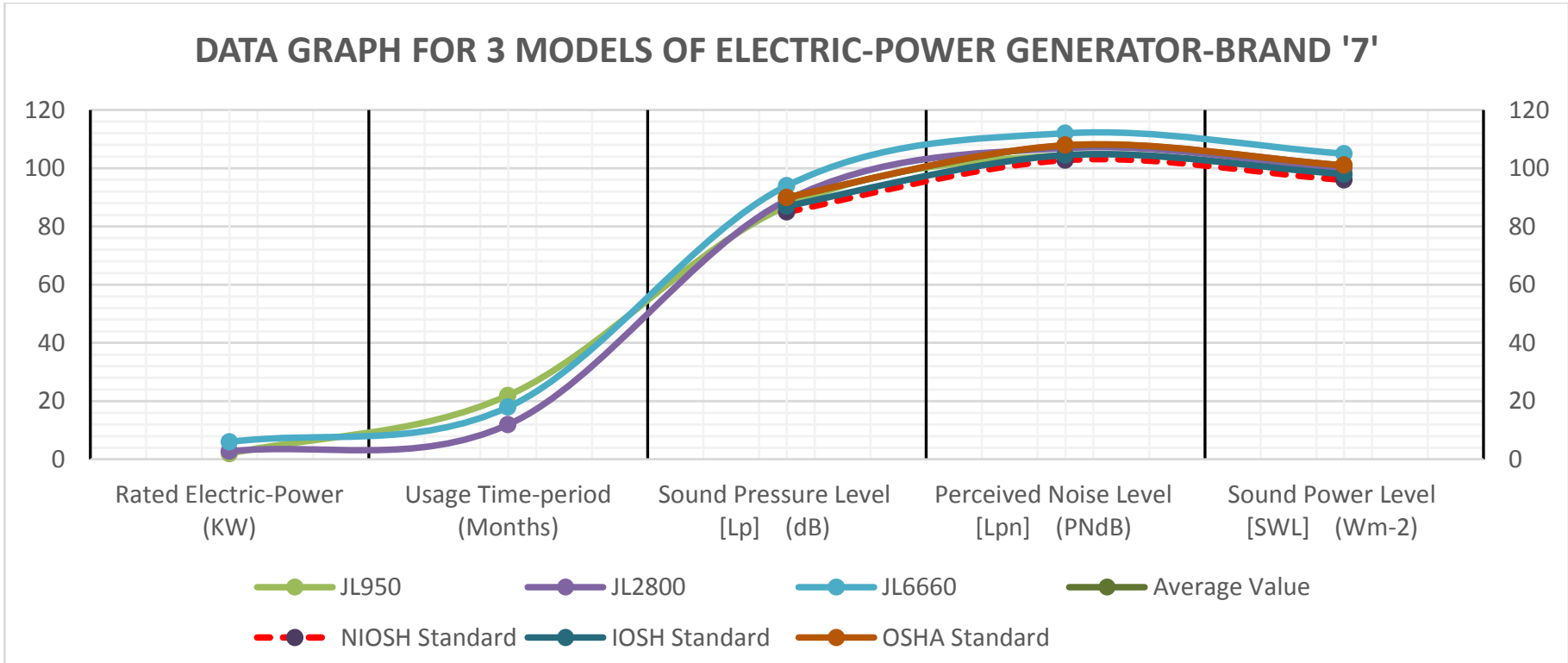

Figure7: Rated Electric-power, Usage Time-period \& Noise parameters of 3 Models manufactured by Generator-brand 7

The four (4) graphs in figures 7-10, collectively and concisely illustrate certain usage data/information and three basic noise parameters of a total number of sixteen (16) Models of generators manufactured by four (4) Generator-brands-comprising of three (3) Models of Generator-brand ' 7 ' in figure 7, four (4) Models of Generator-brand ' 8 ' in figure 8, four (4) Models of Generator-brand ' 9 ' in figure 9, and five (5) Models of Generator-brand ' 10 ' in figure 10. 
DATA GRAPH FOR 4 MODELS OF ELECTRIC-POWER GENERATOR-BRAND '8'

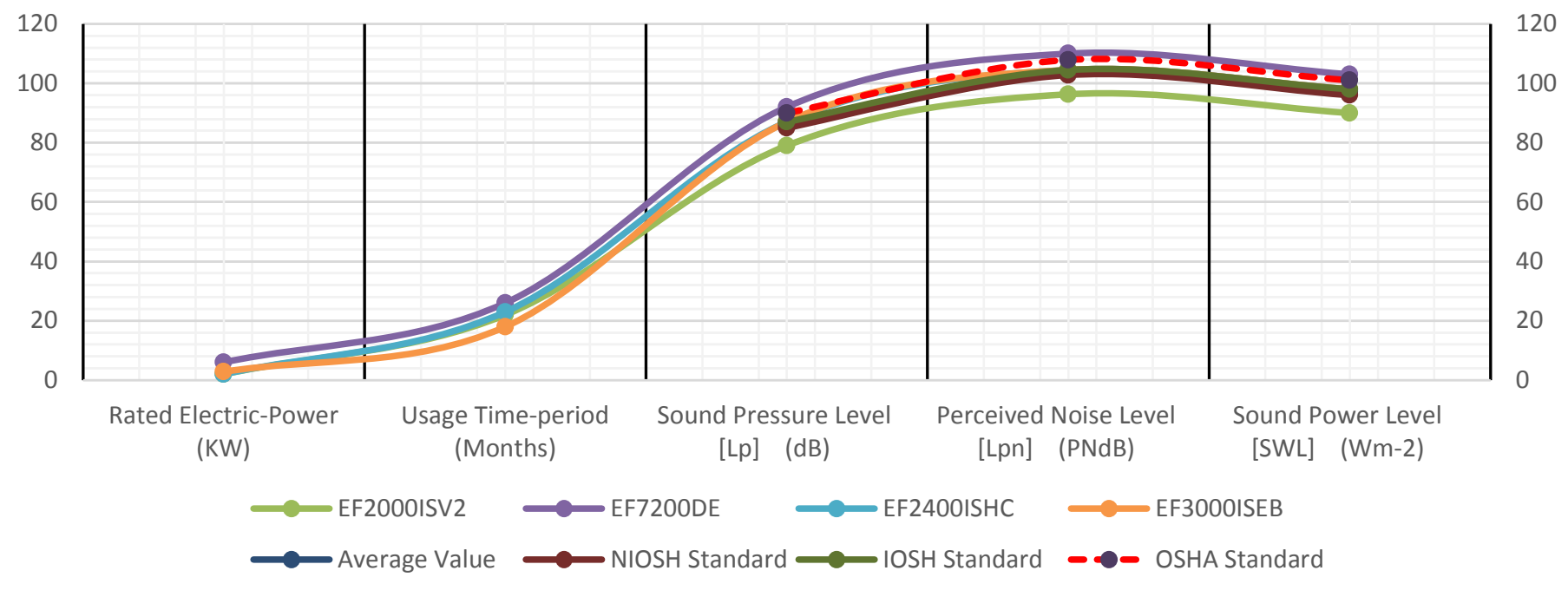

Figure8: Rated Electric-power, Usage Time-period \& Noise parameters of 4 Models manufactured by Generator-brand 8

Now, for each of these four (4) Generator-brands, the Rated electric-power and Usage time duration ranges were: Generatorbrand ' 7 ' ( $0.7 \mathrm{KW}-5.0 \mathrm{KW}, 12$ months -36months $)$, Generator-brand ' 8 ' (2.0KW-6.0KW ,18months - 26months $)$, Generatorbrand ' 9 ' ( $1.1 \mathrm{KW}-6.6 \mathrm{KW}, 15 \mathrm{months}-21$ months $)$ and Generator-brand '10' (2.8KW-12.8KW, 12months -30months $)$.

The calculated Perceived Noise Level ( $L_{P N}$ ) values of the sixteen (16) Models of electricity-generators manufactured by these four (4) Generator-brands were: 100.3PNdB ( JL950), 104.5PNdB ( JL2800 ) and 108.8PNdB ( JL6660) [for Generator-brand '7']; 96.3PNdB (EF2000ISV2), 110.0PNdB (EF7200DE), 104.5PNdB ( EF2400ISHC) and 104.5PNdB (EF3000ISEB ) [for Generator-brand '8']; $102.8 P N d B$ ( SPG1800 ), 104.5PNdB ( SPG3000), 106.9PNdB ( SPG3800E2) and 106.9PNdB ( SPG8500E2 ) [for Generator-brand '9']; and 108.8PNdB ( SV3300 ), 111.0PNdB ( SH6000), 102.8PNdB ( SHT17D ), 110.0PNdB ( SH6500EX) and 108.8PNdB ( SH11000 ) [for Generator-brand '10']. A closer look at the above values and figures 7-10, reveals that: one (1) Model of each of Generator-brand '7' and Generator-brand ' 8 ' exceeded both the IOSH recommended $L_{P N}$-value of $104.5 P N d B$ and the $O S H A$ recommended $L_{P N}$-value of $107.9 P N d B$. However, while all four (4) Models of Generator-brand '9' conformed to (were lesser than or equal to) the $O S H A$ recommended $L_{P N}$-value, two (2) other Models of the same Generator-brand '9' exceeded the IOSH recommended $L_{P N}$-value. Moreover, two (2) Models of Generator-brand '7', and three (3) Models of both Generator-brand ' 8 ' and Generator-brand ' 9 ' were noted to have $L_{P N}$-values which exceeded the $N I O S H$ recommended $L_{P N}$-value of $102.8 P N d B$. In the exclusive case of Generator-brand '10', four (4) Models of electricitygenerators exceeded the standard $L_{P N}$-values of $102.8 P N d B, 104.5 P N d B$ and 107.9PNdB recommended by NIOSH, IOSH and $O S H A$ respectively. 


\section{DATA GRAPH FOR 4 MODELS OF ELECTRIC-POWER GENERATOR-BRAND '9'}

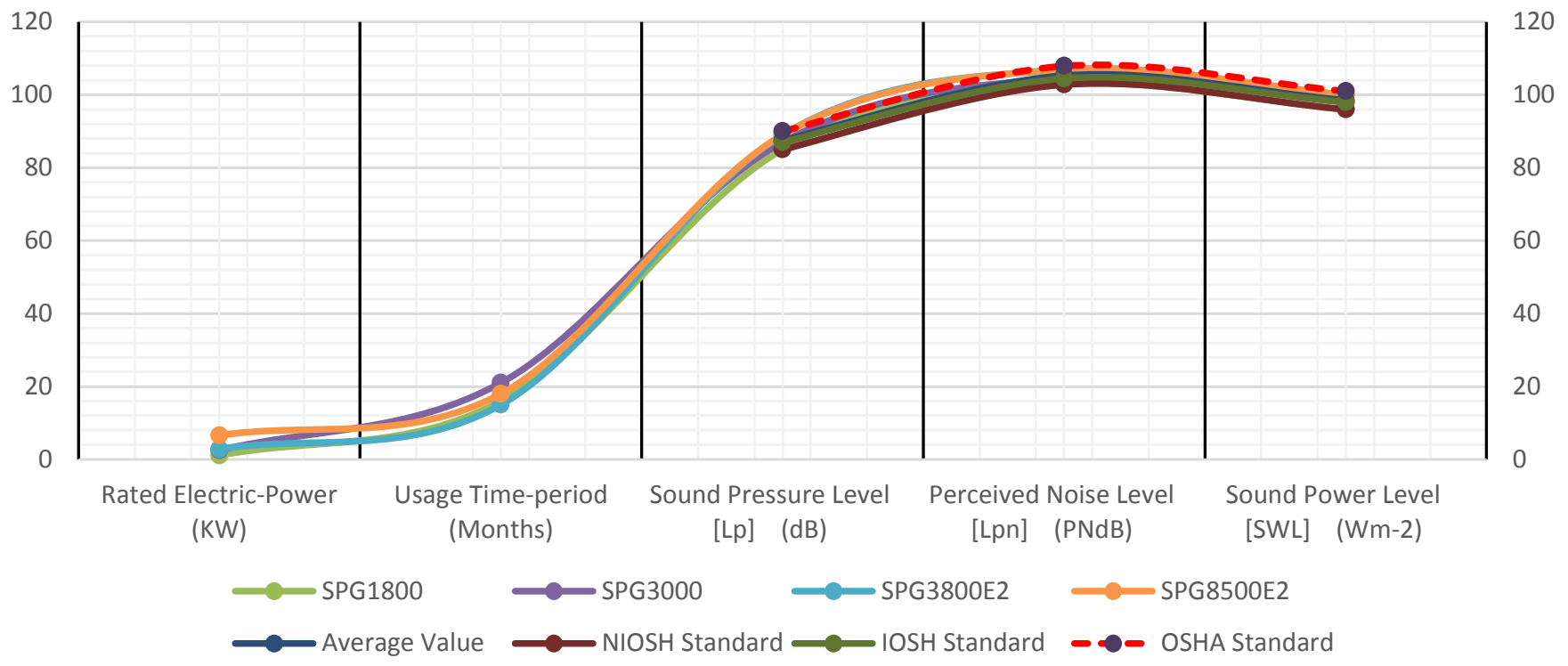

Figure9: Rated Electric-power, Usage Time-period \& Noise parameters of 4 Models manufactured by Generator-brand 9

When the Sound Power Levels ( $S W L$ ) of the various Models of electricity-generators produced by these four (4) Generatorbrands were computed, the computational results were as follows: $93 W^{-2}$ ( $\left.J L 950\right), 98 W^{-2}$ ( $J L 2800$ ) and $102 W m^{-2}$ ( $J L 6660$ ) [for Generator-brand '7']; 90Wm ${ }^{-2}$ ( EF2000ISV2), 103Wm ${ }^{-2}$ ( EF7200DE ), 98Wm ${ }^{-2}$ ( EF2400ISHC ) and 98Wm ${ }^{-2}$ (

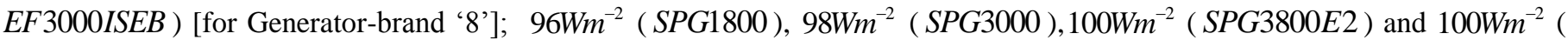
SPG8500E2 ) [for Generator-brand '9']; and $102 \mathrm{Wm}^{-2}$ ( SV3300 ), 104Wm ${ }^{-2}$ ( SH6000 ), 96Wm ${ }^{-2}(S H T 17 D), 103 W m^{-2}($ SH6500EX ) and 102 $\mathrm{Wm}^{-2}$ ( SH11000) [for Generator-brand '10']. In a much similar way, it was observed that: one (1) Model of each of Generator-brand ' 7 ' and Generator-brand ' 8 ' exceeded both the $I O S H$ recommended $S W L$-value of $98 W m^{-2}$ and the OSHA recommended SWL-value of $101 W^{-2}$. However, while all four (4) Models of Generator-brand '9' conformed to (were lesser than or equal to) the OSHA recommended SWL-value, two (2) other Models of the same Generator-brand '9' exceeded the IOSH recommended SWL-value. Moreover, two (2) Models of Generator-brand '7', and three (3) Models of both Generatorbrand '8' and Generator-brand '9' were noted to have $S W L$-values which exceeded the NIOSH recommended $S W L$-value of $96 \mathrm{Wm}^{-2}$. However, in the exclusive case of Generator-brand '10', four (4) Models of electricity-generators exceeded the standard $S W L$-values of $96 \mathrm{Wm}^{-2}, 98 \mathrm{Wm}^{-2}$ and $101 \mathrm{Wm}^{-2}$ recommended by $\mathrm{NIOSH}, \mathrm{IOSH}$ and $O S H A$ respectively. 


\section{DATA GRAPH FOR 5 MODELS OF ELECTRIC-POWER GENERATOR-BRAND '10'}

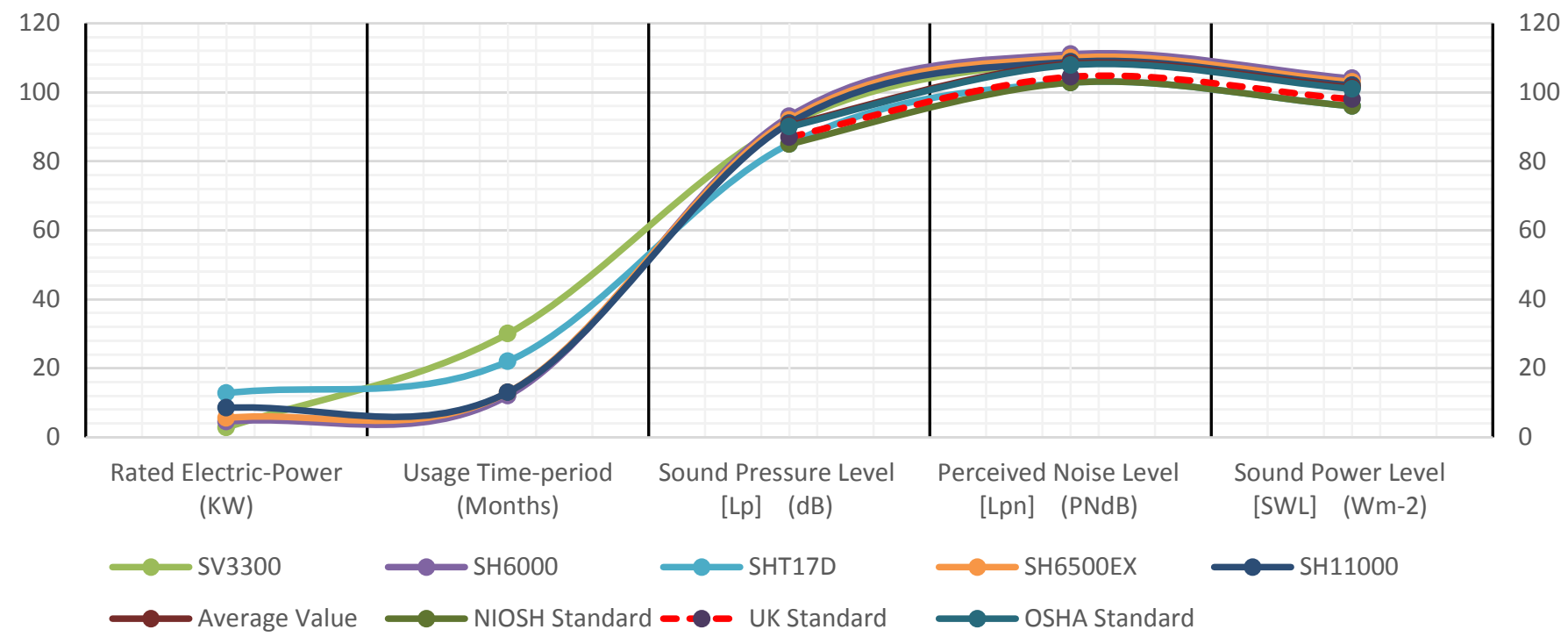

Figure 10: Rated Electric-power, Usage Time-period \& Noise parameters of 5 Models manufactured by Generator-brand 10

Now, a consideration of the plotted data of the measured Sound Pressure Levels $\left(L_{P}\right)$ of the above sixteen (16) Models of electricity-generators manufactured by these same four (4) Generator-brands showed that, two of three Models of generators produced by Generator-brand '7' [ $J L 2800(87 d B)$ and $J L 6660(91 d B)]$, three of four Models of generators produced by Generator-brand '8' [ EF7200DE (92dB), EF2400ISHC (87dB) and EF3000ISEB (87dB )], three of four Models of generators produced by Generator-brand '9' [ $S P G 3000$ (87dB), SPG3800E2 (89dB) and SPG8500E2 (89dB)], and four of five Models of generators produced by Generator-brand '10' [ $S P G 3000$ (87dB), SPG3800E2 (89dB), SPG3000 (87dB) and SPG8500E2 ( $89 d B)$ ], did not conform to (were greater than) the $N I O S H$ recommended $L_{P}$-value of $85 d B$ for 8 hour daily exposure. In addition, one (1) of three (3) Models of generators produced by Generator-brand ' 7 ' [ JL6660(91dB )] , one (1) of four (4) Models of generators produced by Generator-brand '8' [ $E F 7200 D E(92 d B)]$, two (2) of four (4) Models of generators produced by Generator-brand '9' [ SPG3800E2 (89dB) and SPG8500E2 ( 89dB )], and four (4) of five (5) Models of generators produced by Generator-brand '10' [ $S V 3300$ (91dB), SH6000 (93dB ), SH6500EX (92dB) and SH11000 (91dB)], did not conform to (were greater than) the $I O S H$ recommended $L_{P}$-value of $87 \mathrm{~dB}$ for 8 hour daily exposure. Moreover, one (1) of three (3) Models of generators produced by Generator-brand '7' [ $J L 6660(91 \mathrm{~dB})$ ], one (1) of four (4) Models of generators produced by Generatorbrand '8' [ EF7200DE (92dB)], and four (4) of five (5) Models of generators produced by Generator-brand '10' [ SV3300 (91dB ), $S H 6000(93 d B)$ ), $S H 6500 E X(92 d B)$ and $S H 11000(91 d B)$ ], did not conform to (were greater than) the OSHA recommended $L_{P}$-value of $90 \mathrm{~dB}$ for 8 hour daily exposure. Fortunately, however, only one Model of the generators produced by Generatorbrand '10' $[S H T 17 D(85 d B)]$, conformed to (was lesser than or equal to) the $O S H A$ recommended $L_{P}$-value of $90 d B$ for 8hour daily exposure.

\section{CONCLUSION}

The noise-level characterization and comparative experimental assessment of the Sound Pressure Level, Perceived Noise Levels and Sound Power Levels of fifty (50) models of electric-power generators commonly operated in the seven (7) North-central Nigerian cities [of Abuja, Makurdi, Lokoja, Ilorin, Lafia, Minna and Jos] have been carried out on a brand-by-brand basis. Comparatively, the highest recorded average values of all three measured parameters i.e.: $99 d B$ (Sound Pressure Level), 116.5PNdB (Perceived Noise Level) and $110 \mathrm{Wm}^{-2}$ (Sound Power Level) were emitted by generator-model ' ECO8990ES' 
produced by generator-brand ' 3 '. On the other hands, lowest recorded values of all three measured parameters i.e. $73 d B$ (Sound Pressure Level), 91PNdB (Perceived Noise Level) and $84 \mathrm{Wm}^{-2}$ (Sound Power Level) were emitted by two different generatormodels- 'VPG2400' and 'EPG2400', both of which were also produced by the same generator-brand ' 3 '. Furthermore, the noise emitted by electric-power generators [in operational (running) mode] contributes significantly to the overall environmental noise pollution levels in the above cities, this is because the electric-power generators whose noise-levels were investigated had 'Sound Pressure Levels $\left[L_{p}\right.$ ]' ranging from 73-99dB, 'Perceived Noise Levels [ $L_{p n}$ ]' ranging from 91.0-116.5PNdB and 'Sound Power Levels [ $S W L$ ]' ranging from $84-110 \mathrm{Wm}^{-2}$. Now, it is obvious that majority ( $80 \%$ ), two-thirds ( $66 \%$ ) and less than half ( $42 \%)$ of these value-ranges exceeded each set of three standard maximum limits/values i.e. $L_{p}(85 d B, 87 d B$ and $90 \mathrm{~dB}) ; L_{p n}(102.8 P N d B, 104.5 P N d B$ and $107.9 \mathrm{~dB})$ and $S W L\left(96 \mathrm{Wm}^{-2}, 98 \mathrm{Wm}^{-2}\right.$ and $\left.101 \mathrm{Wm}^{-2}\right)$ recommended by the 'National Institute for Occupational Safety \& Health ( NIOSH )', the 'Institution of Occupational Safety \& Health ( IOSH )', and then, the 'Occupational Safety \& Health Administration (OSHA)' respectively for 8hour safe daily human exposure. This, therefore, constitutes a major hazardous exposure, which would most certainly adversely affect the health and wellbeing of the cities' residents over time, if left unchecked/unmitigated.

\section{RECOMMENDATIONS}

In order to reduce the occurrence of the presently rising cases of environmental noise pollution emitted by electric-power generators used in the North-central Nigerian cities of Abuja, Makurdi, Lokoja, Ilorin, Lafia, Minna \& Jos [and if possible across the entire length and breadth of the country]; with its accompanying ill-health implications, we hereby make the following recommendations to the Nigerian government:

i. The government should enforce the implementation of environmental noise control policy across the country.

ii. As an interim control measure, the government should place impose import tariffs on electric-power generators known to have high noise-emission levels, so as to discourage their importation, while the option of an outright ban on their importation could be adopted in the near future as a long-term measure.

iii. Prospective buyers of electric-power generators should be properly educated by the appropriate local authorities and national regulatory bodies/agencies of government, on the ways/methods to identify electric-power generators with low noise-emission levels.

iv. The operation/use of old and/or unserviceable electric-power generators should be discouraged.

v. A spacing of not less than seven (7) meters should always be maintained between a running (operational) electric-power generator and the person(s) residing or working in the vicinity of this running (operational) electric-power generator.

vi. Further research on this subject-matter of 'Electric-power generator noise emission/pollution levels' is advised.

\section{ACKNOWLEDGEMENT}

The authors are sincerely grateful to GOD almighty for this infinite grace that has made this possible. We are also thankful to 'Hafalix Nigeria Limited (Engineering, Construction, Maritime \& Logistics),' Lagos, and 'Redsav Nigeria Limited', Lagos; for their invaluable support during the course of this research project.

\section{REFERENCES}

1. O. Ibhadode, P. Ibhadode, A.F. Okougha, I.I. Umanah, F.O. Aitanke, and S.A.B. Fiyebo, "Hazards Assessment Analyses of Fossil-Fuel Generators: Holistic-Study of Human Experiences and Perceptions in South-Southern Nigeria." Journal of Sustainable Development Studies, vol. 9, September 2016, pp.153-242.

2. O. Ibhadode, I.T, Tenebe, P.C. Emenike, O.S. Adesina, A.F. Okougha, and F.O. Aitanke, "Assessment of Noise-levels of Generator-sets in Seven Cities of South-Southern Nigeria." African Journal of Science, Technology, Innovation and Development, vol. 10, January 2018, pp.125-135. DOI: 10.1080/20421338.2017.1400711

3. A. Adekunle, G.O. Asaolu, K. Adiji, and H.A. Bamiduro, "Impacts of Electrical Hazards on Nigerian Construction Industries with a View to Provide Safety Measures-Case Study of Kaptron Technologies." Journal of Sustainable Development Studies, vol. 9, September 2016, pp.267-289.

4. W. Passchier-Vermeer and W.F. Passchier, "Noise Exposure and Public Health." Environmental Health Perspectives, vol. 108, March 2000, pp.123-131. DOI: 10.2307/3454637 
5. K. Sørensen, S. Van den Broucke, J.M. Pelikan, J. Fullam, G. Doyle, Z. Slonska, B. Kondilis, V. Stoffels, R.H. Osborne, and H. Brand, "Measuring health literacy in populations: illuminating the design and development process of the European Health Literacy Survey Questionnaire (HLS-EU-Q).” BMC Public Health, vol. 13, October 2013, pp.948-957. DOI: 10.1186/1471-2458-13-948

6. M.S. Hammer, T.K. Swinburn, and R.L. Neitzel, "Environmental Noise Pollution in the United States: Developing an Effective Public Health Response." Environ Health Perspect, vol. 122, February 2014, pp.115-119. DOI: 10.1289/ehp.1307272

7. K. Parvathi and A. Navaneetha Gopalakrishnan, "Studies on Control of Noise from Portable Power Generator." Proceedings of the 3rd International Conference on Environment and Health, Chennai, India, 15th-17th December 2003, pp.328-338.

8. T.Z. John and G.A. Dewan, "Noise Levels and Noisiness of some Power Generators in Federal College of Education Environs, Pankshin, Plateau State Nigeria.” Journal of Environment and Earth Science, vol. 5, December 2015, pp.5660.

9. O. Ibhadode, O.S. Oyedepo, A.S. Ogunro, A. Joseph, S.O. Banjo, I.I. Umanah, E.S. Apeh, and A.R. Ayoola, “An Experimental-assessment of Human Exposure-levels to Aircraft Noise-hazards in the Neighbouring-environments of four Nigerian Airports." IOP Conf. Ser.: Mater. Sci. Eng. 413 012080, vol. 413, DOI: 10.1088/1757-899X/413/1/012080

10. R.W. Cantrell, "Effects of Noise Exposure." AGARD Conference Proceedings No. 171, Effects of Long Duration Noise Exposure on Hearing and Health, NATO, vol. 171, November 1975.

11. Commonwealth of Australia, "The health effects of environmental noise-other than hearing loss." enHealth Council (New South Wales Health Department) Report, No. 3311 (JN 7845), Department of Health and Ageing, Population Health Division, Australia, May 2004, pp. 1-9. http://enhealth.nphp.gov.au/council/ pubs/pubs.htm

12. D. Pramendra and S. Vartika, "Environmental Noise Pollution Monitoring and Impacts on Human Health in Dehradun City, Uttarakhand, India.” Civil and Environmental Research, vol. 1, January 2011, pp.32-39.

13. A. H. Suter, "Noise and its effects: effects of noise on sleep." Administrative Conference of the United States, November 1991. www.nonoise.org/library/suter/suter.htm

14. WHO, "Guidelines for Community Noise.", World Health Organization Report, WHO Occupational and Environmental Health Team, Geneva, 1999.

15. J.Z. Told, N.M.D. Chagok, L.D. Domtau, T.P. Form, and Y.H. Ngadda, "Sound Pressure, Power Level, Noisiness and Perceived Noise Level of some commonly used Generators in Pankshin Metropolis of Plateau State Nigeria." Civil and Environmental Research, vol. 3, September 2013, pp.45-52.

16. O. Ibhadode, F.A. Okougha, C.O. Nwafor, and N. Essang, "An Experimental-study on Ventilation of Public Schools in Akure, Oshogbo and Ado-ekiti Cities in South-western Nigeria." IOSR Journal of Mechanical and Civil Engineering, vol. 14, September 2017, pp.34-43. DOI: 10.9790/1684-1405013443

17. W.T.W. Cory, "Relationship between Sound Pressure and Sound Power Levels." Eurovent WGI, 2016. http://www.euroventcertification. 